\title{
Demography of adolescent health care delivery and training in Europe
}

\author{
Oya Ercan • Mujgan Alikasifoglu • Ethem Erginoz • \\ Jan Janda • Pavel Kabicek • Armido Rubino • \\ Andreas Constantopoulos • Ozdemir Ilter • \\ Mehmet Vural
}

Received: 21 February 2008 / Accepted: 6 May 2008 / Published online: 2 July 2008

(C) The Author(s) 2008

\begin{abstract}
Background We aimed to determine the status of and factors associated with adolescent health care delivery and training in Europe on behalf of the European Paediatric Association-UNEPSA.

Materials and methods A questionnaire was mailed to the presidents of 48 national paediatric societies in Europe. For statistical analyses, non-parametric tests were used as appropriate.

Results Six of the countries had a paediatric (PSPCA), 14 had a combined and nine had a general practitioner/family
\end{abstract}

Electronic supplementary material The online version of this article (doi:10.1007/s00431-008-0759-1) contains supplementary material, which is available to authorized users.

\section{O. Ercan}

Department of Paediatrics,

Divisions of Adolescent Medicine and Endocrinology,

Istanbul University, Cerrahpasa Medical Faculty,

Istanbul, Turkey

\section{Alikasifoglu}

Department of Paediatrics, Division of Adolescent Medicine, Istanbul University, Cerrahpasa Medical Faculty,

Istanbul, Turkey

\section{E. Erginoz}

Department of Public Health, Istanbul University,

Cerrahpasa Medical Faculty,

Istanbul, Turkey

J. Janda

1st Department of Paediatrics, University Hospital Motol,

Prague, Czech Republic

\section{P. Kabicek}

Department of Paediatrics and Adolescent Medicine, 1st Faculty of Medicine, Charles University Prague,

Prague, Czech Republic doctor system for the primary care of adolescents (GP/ FDSA). Paediatricians served children 17 years of age or older in 15 and 17, up to 16 years of age in three and six, and up to 14 years of age in six and six countries in outpatient and inpatient settings, respectively. Fifteen and 18 of the countries had some kind of special inpatient wards and outpatient clinics for adolescents, respectively. Twentyeight of the countries had some kind of national/governmental screening or/and preventive health programmes for adolescents. In countries with a PSPCA, the gross national income (GNI) per capita was significantly lower than in
A. Rubino

Facoltà di Medicina e Chirurgia,

Università degli Studi di Napoli Federico II,

Naples, Italy

\author{
A. Constantopoulos \\ Department of Paediatrics, \\ Athens University, \\ Athens, Greece \\ O. Ilter · M. Vural \\ Department of Paediatrics, \\ Istanbul University, \\ Cerrahpasa Medical Faculty, \\ Istanbul, Turkey
}

M. Vural $(\bowtie)$

Nisantasi Ihlamur Yolu,

2 Cehreli apt. 67/9, Topagaci,

80200 Istanbul, Turkey

e-mail: vuralm@istanbul.edu.tr 
those with a GP/FDSA, and the mean upper age limit of adolescents was significantly higher than in those with the other systems. In the eastern part of Europe, the mortality rate of 10-14 year olds was significantly higher than that in the western part $(p=0.008)$. Training in adolescent medicine was offered in pre-graduate education in 14 countries in the paediatric curriculum and in the context of paediatric residency and $\mathrm{GP} /$ family physician residency programmes in 18 and nine countries, respectively. Adolescent medicine was reported as a recognised subspecialty in 15 countries and as a certified subspecialty of paediatrics in one country. In countries with a PSPCA, paediatric residents were more likely to be educated in adolescent medicine than paediatric residents in countries with a GP/FDSA.

Conclusion The results of the present study show that there is a need for the reconstruction and standardisation of adolescent health care delivery and training in European countries. The European Paediatric Association-UNEPSA could play a key role in the implementation of the proposals suggested in this paper.

Keywords Adolescent health · Europe · Training

\begin{tabular}{|c|c|}
\hline \multicolumn{2}{|c|}{ Abbreviations } \\
\hline AT & Adolescent training \\
\hline $\mathrm{CZ}$ & Czech Republic \\
\hline EPA & European Paediatric Association \\
\hline EU & European Union \\
\hline EuTEACH & $\begin{array}{l}\text { European training in effective adolescent care } \\
\text { and health }\end{array}$ \\
\hline FD & Family doctor \\
\hline GNI & Gross national income per capita \\
\hline GP & General practitioner \\
\hline GPCME & $\begin{array}{l}\text { General practitioner/family physician contin- } \\
\text { uous medical education }\end{array}$ \\
\hline GP/FDSA & $\begin{array}{l}\text { General practitioner/family doctor system for } \\
\text { the primary care of adolescents }\end{array}$ \\
\hline GPR & $\begin{array}{l}\text { General practitioner/family physician } \\
\text { residency }\end{array}$ \\
\hline HIV & Human immunodeficiency virus \\
\hline IPA & International Paediatric Association \\
\hline $\mathrm{PC}$ & Primary care \\
\hline PCME & Paediatric continuous medical education \\
\hline PR & Paediatric residency \\
\hline PSPCA & $\begin{array}{l}\text { Paediatric system for the primary care of } \\
\text { adolescents }\end{array}$ \\
\hline STI & Sexually transmitted infections \\
\hline UK & United Kingdom \\
\hline UNEPSA & $\begin{array}{l}\text { The Union of National European Paediatric } \\
\text { Societies and Associations }\end{array}$ \\
\hline USA & The United States of America \\
\hline WHO & The World Health Organization \\
\hline
\end{tabular}

\section{Introduction}

Adolescence is a period of childhood with rapid developmental changes. During adolescence, experimentation with taking adult roles, relationships and responsibilities can put adolescents at risk. Key health challenges during adolescence are quite different to those during childhood and include injuries, sexual and reproductive health, unhealthy behaviours linked to the use of substances and to diet and physical activity, and mental health [9]. These challenges make adolescents individuals with special needs.

Accordingly, one of the World Health Organization's (WHO) seven priority areas for action in the European context for improving the health and development of children and adolescents is adolescent health [37]. According to WHO policies, programmes and health service systems should be in place to work towards the following targets: healthy lifestyle development; prevention of risky behaviours; youth-friendly health services for reproductive health, including contraception, the prevention of unwanted pregnancies and the prevention and care of sexually transmitted infections (STI), human immunodeficiency virus (HIV) and other infectious diseases; youth-friendly counselling and health services for other health problems, such as violence and abuse; protection from exploitation and hazardous labour practices; the prevention of sexual, physical and mental abuse; healthy school environments that facilitate physical and psychological well-being; supportive home and community environments; the control of inappropriate adolescent-centred marketing; full immunisation; injury prevention; and relationship and parenthood education [37].

As confidentiality is an indispensable element of adolescent health care, services aimed at reaching these targets should include confidentiality [11].

Besides, the UN Convention on the Rights of the Child obligates the protection of children's rights by setting standards in health care with a core principle of nondiscrimination in their implementation [33]. The convention also states the upper age limit of childhood as 18 years.

By agreeing to undertake the obligations of the Convention, national governments have committed themselves to protecting and ensuring children's rights, and they have agreed to hold themselves accountable for this commitment before the international community [33].

The European Paediatric Association-UNEPSA (the Union of National European Paediatric Societies and Associations), founded in 1976, represents more than three quarters of all European-continent countries [4]. It represents European paediatrics in the International Paediatric Association (IPA), stimulates professional contact between paediatricians from eastern and western Europe, and 
analyses various policies of paediatric care in continental Europe [10, 23].

Due to the appeal of the fact that adolescent health is one of the WHO's priority areas for action, to improve the health and development of children and adolescents, in this paper, on behalf of the European Paediatric AssociationUNEPSA, we aimed to determine the status of adolescent health care and training in Europe and the factors that were associated with adolescent health care and training, with the hope that the conclusions of this study will have practical implications in the fulfilment of the obligations of the UN Convention on the Rights of the Child.

\section{Methods}

Instrument

A questionnaire, which partly comprised the questions used by Katz et al. [23] in a study that investigated the demography of paediatric primary care in Europe, was developed by two members of the Turkish Paediatric Association. Contributions were requested from experts based in different countries. A European Paediatric Association-UNEPSA workshop was held on 26th June 2004 in Istanbul, Turkey, during the annual congress of the Turkish Paediatric Association to finalise the last version of the questionnaire.

The questionnaire is composed of nine specific questions regarding the delivery of care and eight specific questions regarding training in adolescent medicine (Appendix 1, available in the electronic supplementary material). The classification of the countries according to the organisation of adolescent primary health care delivery was made as indicated below.

Primary care systems for adolescents

- Paediatric: more than $75 \%$ of children under the care of paediatricians

- General practitioner/family doctor system: more than $75 \%$ of children under the care of a general practitioner/ family doctor

- Combined: both the paediatrician and the general practitioner/family doctor offer care to almost equal numbers of children $(50 \pm 25 \%)$

Questions on the number of children in the country by age groups, the number of general practitioner/family doctors and paediatricians in the country, adolescent mortality rates (for groups 10-14 and 15-19 years of age) and percentages of adolescent mortality rates due to suicide, unintentional injuries, homicide, and obesity, number of new gonorrhoea and syphilis cases, birth rate and the rate of artificial termination of pregnancy among adolescents for the year 2003 were also included in the questionnaire (Appendix 1).

\section{Procedures}

Letters explaining the purpose of the study and questionnaires were e-mailed to the presidents of all member countries of the European Council and Israel beginning from October 2005 [29]. National presidents were asked to choose a distinguished adolescent health specialist from their country in order to respond to this questionnaire in a most accurately as possible manner under their patronage. Reminding e-mails were sent regularly in order to stimulate the participation of non-responding countries. Countries which did not respond before October 2006 were excluded from the study.

Information on the gross national income (GNI) per capita were obtained from the web site of the World Bank. Countries were divided into four groups according to their GNI per capita in the year 2005 as proposed by the World Bank [35].

\section{Statistical analysis}

The Kruskall-Wallis one-way analysis of variance (ANOVA) test, Chi-square test, Fisher's exact test and Pearson's correlation test were used as appropriate.

\section{Results}

Responses were received from 29/48 countries (19/27 EU and $10 / 21$ non-EU countries). The total population of the responding countries in the European Union comprised $85 \%$ of the population of the EU. The total population of the non-EU responding countries comprised $91 \%$ of the whole population of non-EU countries. Similar percentages were obtained for EU and non-EU countries concerning their adolescent populations; $83 \%$ and $90 \%$, respectively. The results reported were from all 29 responding countries unless otherwise specified.

\section{Delivery of care}

Data on the demography of adolescent care are presented in Table 1 .

The proportion of adolescents with respect to the total population varied from $9.99 \%$ (Italy) to $20.03 \%$ (Albania).

There was a weak negative correlation between the proportion of adolescents with respect to the total population and the GNI ( $r=-0.54, p=0.003)$. 
Table 1 Demography of adolescent care

\begin{tabular}{|c|c|c|c|c|c|}
\hline & Total $(n)$ & Min. & Country & Max. & Country \\
\hline No. of paediatricians & 160,027 & 54 & Luxemburg & 60,400 & Russia \\
\hline Child population ( $0-18$ years) & $171,589,143$ & 107,930 & Luxemburg & $34,153,102$ & Russia \\
\hline No. of adolescents (10-19 years) & $93,402,452$ & 51,291 & Luxemburg & $20,710,733$ & Russia \\
\hline Median no. of adolescents/paediatrician & 747 & 266 & Georgia & 3,253 & Turkey \\
\hline Median no. of adolescents/PC paediatrician & 1,059 & 386 & Greece & 20,175 & Norway \\
\hline No. of GP/FD & 424,485 & 184 & Georgia & 102,911 & Germany \\
\hline Median no. of adolescents/GP/FD & 219 & 83 & France & 6,091 & Russia \\
\hline
\end{tabular}

$\mathrm{PC}=$ primary care; $\mathrm{GP}=$ general practitioner; $\mathrm{FD}=$ family doctor

The distribution of primary care systems for adolescents in Europe is presented in Fig. 1. In the countries with a paediatric system, the median number of adolescents per paediatrician was 848 (minimum: 386, maximum: 936). In the countries with a general practitioner/family doctor system, the median number of adolescents per general practitioner/family doctor was 204 (minimum: 153, maximum: 250).

The type of primary care system of adolescents was significantly associated with the GNI per capita of the country $(p=0.017)$. The Dunn test revealed that those countries with a PSPCA had significantly lower GNIs per capita than those countries with a GP/FDSA (mean difference: $\$ 23,346.67 ; 95 \%$ CI: $\$ 9,190.37-\$ 37,503.0$; $p=0.003$ ).

Data on the demography of adolescent care given by paediatricians are presented in Tables 2 and 3. Four countries (Denmark, Estonia, Portugal and the Netherlands) did not have any paediatricians working at the primary care. In Switzerland, it was stated that, in reality, there was no clear definition. It was indicated that, according to a previous study, the upper age limit of patients in paediatric practice depended mostly on the number of years that a

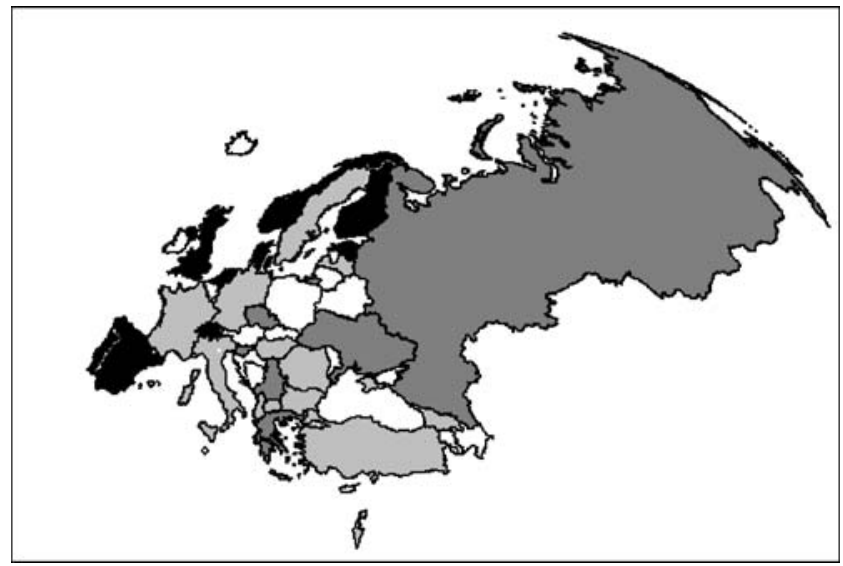

Fig. 1 The distribution of primary care systems for adolescents in Europe; white=non-responding country, black=general practitioner/ family doctor system, dark grey=paediatric system, light grey= combined system paediatrician had been working in that setting. In the countries with a PSPCA, the mean upper age limit (18.66 \pm 0.81 years) of adolescents was significantly higher than those of countries with the other two systems (GP/FDSA: $15.5 \pm 1$ years; combined system: $15.85 \pm$ 3.52 years) (both $p<0.05$ ).

While 15 of the 29 countries had some kind of special inpatient wards for adolescents, 12 did not. Two of the countries responded as "I do not know" (Denmark, Luxemburg). Eighteen of the countries had some kind of special outpatient clinic for adolescents, while nine did not. One country (Denmark) answered this question as "I do not know." In Norway, as a part of the primary care system, school health services, mostly run by school nurses, gave service to children up to 18 years of age.

Data on the demography of primary health care for adolescents regarding "National screening and/or preventive services provided to adolescents" are presented in Table 4.

Twenty-eight of the countries had some kind of national/ governmental screening or/and preventive health programmes for adolescents. There were no such programmes in one country (Greece). There was no relationship between the type of primary care system for adolescents and the total number of screening and/or preventive programmes given to the adolescents $(p=0.87)$.

Mortality and morbidity

Data on adolescent mortality and morbidity are presented in Tables 5 and 6, respectively. There was a strong correlation

Table 2 Demography of adolescent care given by paediatricians I

\begin{tabular}{|c|c|c|}
\hline \multirow{2}{*}{$\begin{array}{l}\text { Percentage seen } \\
\text { by paediatricians }\end{array}$} & \multirow{2}{*}{$\frac{10-14 \text { years old }}{\text { Countries }(n)}$} & \multirow{2}{*}{$\frac{15-19 \text { years old }}{\text { Countries }(n)}$} \\
\hline & & \\
\hline$>90$ & $10 / 25$ & $4 / 23$ \\
\hline $51-90$ & $6 / 25$ & $4 / 23$ \\
\hline $10-50$ & $6 / 25$ & $6 / 23$ \\
\hline$<10$ & $3 / 25$ & $9 / 23$ \\
\hline
\end{tabular}


Table 3 Demography of adolescent care given by paediatricians II

\begin{tabular}{llll}
\hline Upper age limit for paediatric care & Outpatient & & Inpatient \\
\cline { 2 - 2 } & Countries $(n)$ & & Countries $(n)$ \\
\hline 14 years & $6 / 24$ & $6 / 29$ \\
16 years & $3 / 24$ & $6 / 29$ \\
$\geq 17$ years & $15 / 24$ & $17 / 29$ \\
\hline
\end{tabular}

between the 10-14 years old group mortality rate and the $15-19$ years old group mortality rate $(r=0.71 ; p<0.0001)$. However, there was a weak correlation between the infant mortality rate and the 10-14 years old mortality rate $(r=0.457 ; p=0.019)$ and no correlation between the infant mortality rate and the 15-19 years old mortality rate.

When the countries were divided into three groups (lower- and upper-middle and high income) according to their GNI, there were significant differences between the mortality rates of $10-14$ year olds $(p=0.017)$. In the lowermiddle income countries, the 10-14 years of age mortality rates were significantly higher than those in higher income countries with the post-hoc Dunn test ( $p=0.004)$.

Those countries which were located in the western part of Europe had significantly higher GNIs than those

Table 4 Demography of primary health care for adolescents

\begin{tabular}{llll}
\hline $\begin{array}{l}\text { National screening and/or } \\
\text { preventive services offered } \\
\text { to adolescents }\end{array}$ & Yes & & $\begin{array}{l}\text { Confidential } \\
\text { care (yes) }\end{array}$ \\
\cline { 2 - 2 } Immunisation & Countries $(n)$ & Countries $(n)$ \\
Smoking & 23 & 7 \\
Monitoring growth & 23 & 20 \\
Drug use & 21 & \\
Pregnancy prevention & 21 & 18 \\
Contraception & 21 & \\
Elective abortion & & 20 \\
Alcohol drinking & & 13 \\
STIs & 20 & 19 \\
HIV & 20 & 18 \\
Obesity & 19 & 16 \\
Hypertension & 16 & \\
Eating disorders & 15 & \\
Tuberculosis & 14 & \\
Learning or school problems & 13 & \\
Child abuse & 13 & \\
Emotional problems (depression) & 12 & 11 \\
Hyperlipidaemia & 11 & \\
Suicide & 9 &
\end{tabular}

In Switzerland, health nurses and school doctors mostly worked without parental guidance. Cooperation with parents and their being informed depended a lot on the adolescent himself/herself. Health care professionals also needed to evaluate if information passed on to parents were needed countries in the eastern part of Europe (mean difference: $\$ 24,430.19 ; 95 \%$ CI: $\$ 15,515.9-\$ 33,344.5 ; p=0.0001)$. In the eastern part of Europe, the mortality rate of 10-14 year olds was significantly higher than that in the western part $(p=0.008)$.

The type of primary care system for adolescents was associated with neither the 10-14 years of age mortality rate nor with the $15-19$ years of age mortality rate $(p=0.60$ and $p=0.53$, respectively).

\section{Organisation of training}

Pre-graduate education in adolescent medicine was offered in 14 countries in the paediatric curriculum. Training in adolescent medicine was offered in 18 countries in the context of paediatric residency programmes. Questions about adolescent medicine were included in paediatric board/certification examinations in 19 countries, while in seven, they were not. Switzerland answered this question as "I do not know." There were no paediatric board/certification examinations in Norway and Spain.

Training in adolescent medicine was offered in nine countries in the context of GP/family physician residency programmes, while in 17 , it was not. Three countries (Norway, Luxemburg and Albania) answered this question as "I do not know." Questions about adolescent medicine were included in general practitioner/family doctor board/ certification examinations in eight countries, while in 11 , they were not. Seven countries (Albania, Sweden, Israel, Switzerland, Estonia, Slovenia and Hungary) answered this question as "I do not know." There was no general practitioner/family doctor board/certification examination in three countries (Norway, Netherlands and Spain).

Postgraduate education in adolescent medicine was offered to paediatricians in 25 countries and to general practitioners/family doctors in 16 countries. In Fig. 2, the proportions of countries with training in adolescent medicine at different levels and categories are presented.

Adolescent medicine was reported as a recognised subspecialty in 15 of the countries and as a certified subspecialty in two countries (Switzerland and the Czech Republic). Adolescent medicine was indicated as a certified subspecialty of paediatrics only in the Czech Republic. Switzerland did not indicate in which specialty it had a certified adolescent medicine subspecialty. Adolescent medicine was neither a certified nor a recognised subspecialty in ten of the countries (Serbia, Norway, Ukraine, the UK, the Netherlands, Latvia, Germany, Finland, Bulgaria and Luxemburg). One country answered this question as "I do not know" (Albania). Denmark did not answer this question.

There were no significant differences between the paediatric system for the primary care of adolescents 
Table 5 Mortality

\begin{tabular}{|c|c|c|c|c|c|c|c|c|}
\hline \multirow[b]{2}{*}{ Country } & \multicolumn{2}{|c|}{ Total per 1,000} & \multicolumn{2}{|l|}{ Suicide \% } & \multicolumn{2}{|c|}{ Unintentional injury $\%$} & \multicolumn{2}{|l|}{ Homicide \% } \\
\hline & $10-14$ years & $15-19$ years & $10-14$ years & $15-19$ years & $10-14$ years & 15-19 years & $10-14$ years & $15-19$ years \\
\hline Albania & 0.46 & 0.5 & & & 40 & 51 & & \\
\hline Bulgaria & 0.32 & 0.44 & 4 & 4 & 45 & 55 & & \\
\hline $\mathrm{CZ}$ & 0.1 & 0.4 & 9 & 14.2 & 29.5 & 55.6 & 6.8 & 1 \\
\hline Denmark & 0.44 & 1.93 & 10 & 8.6 & 30 & 47 & 0 & 5 \\
\hline Estonia & 0.34 & 0.69 & 12.5 & 16.2 & 21.8 & 52.7 & 3.1 & 4 \\
\hline Finland & 0.16 & 0.48 & 9 & 27 & 45 & 44 & 0 & 3 \\
\hline France & 0.16 & 0.48 & 7 & 11 & 25 & 44 & & \\
\hline Georgia & & 0.65 & & 0.006 & & 3 & & 2 \\
\hline Germany & 0.1 & 0.36 & 5 & 13 & 16.2 & 41.2 & 1 & 1 \\
\hline Greece & 0.15 & 0.58 & & 3.3 & 6.8 & 52.3 & 0.8 & 0.8 \\
\hline Hungary & 0.2 & 0.4 & 7.1 & 19.4 & 36.7 & 35.6 & 1.2 & 2 \\
\hline Israel & 0.2 & 0.4 & & 15 & & 37 & & 4 \\
\hline Italy & 0.134 & 0.374 & & & 15 & 55 & & \\
\hline Latvia & 0.218 & 0.56 & 3 & 9 & 61 & 65 & 3 & 3 \\
\hline Luxembourg & 0.239 & 0.804 & 0.9 & 7.4 & & & & \\
\hline Macedonia & 0.5 & 0.9 & 0 & 5.53 & 4.65 & 18.45 & 0.24 & 4.01 \\
\hline Netherlands & 0.118 & 0.266 & 7.6 & 12.7 & 31 & 42.6 & 0.84 & 5 \\
\hline Norway & 0.16 & 0.34 & 16 & 30 & 30 & 39 & 2 & 1.7 \\
\hline Portugal & 0.22 & 0.49 & & & & & & \\
\hline Romania & 0.34 & 0.58 & & & & & & \\
\hline Russia & 0.5 & 1.4 & 8 & 17 & 14 & 17 & & \\
\hline Serbia & & & & & & & & \\
\hline Slovenia & 0.1 & 0.53 & 9.1 & 18.8 & 36.4 & 44.9 & 9.1 & 1.4 \\
\hline Spain & 0.15 & 0.39 & & & & & & \\
\hline Sweden & 0.1 & 0.23 & 5 & 21 & 36 & 36 & 0 & 0.1 \\
\hline Switzerland & 0.3 & 0.7 & & 22.22 & & 33.3 & & 1.98 \\
\hline Turkey & 0.14 & 0.26 & 3.76 & 18.04 & 12.16 & 13.89 & & \\
\hline UK & 0.13 & 0.4 & 14 & 20 & 23 & 30 & & \\
\hline
\end{tabular}

(PSPCA) and the general practitioner/family doctor system for the primary care of adolescents (GP/FDSA) with respect to offering pre-graduate education on adolescent medicine in the paediatric curriculum, offering general practitioner/family doctor residents education on adolescent medicine and offering postgraduate education programmes to both paediatricians and general practitioners/family doctors. However, in countries with a PSPCA, paediatric residents were more likely to be educated in adolescent medicine than paediatric residents in countries with GP/FDSA $(p=0.04)$.

\section{Discussion}

In this study, we describe the current status of adolescent medicine in Europe and then we tried to find out which is the best in addressing adolescents' health needs.

Under the UN Convention on the Rights of the Child, adolescents' rights to a safe and supportive environment and to have a high standard of health care are being acknowledged, yet, the results of this study indicate that not every adolescent in Europe shares these simple rights [34].

\section{Delivery of care}

As in the study by Katz et al. [23], we also found that three different systems of paediatric primary care existed in Europe for adolescents.

Our results also showed that there was no agreement on the upper age limit of the patients cared for by paediatricians in neither paediatric outpatient nor inpatient practices in different countries. Thus, there seems to be no consensus on who the preferred doctor to treat adolescents is. Burgio and Ottolenghi [6] found similar results in 1994 for 29 European countries. There is an argument in the academic literature on this issue. Churchill et al. [7] stated that specific concerns might be better addressed within the context of routine care rather than providing separate 
Table 6 Morbidity

\begin{tabular}{|c|c|c|c|c|c|c|c|c|c|c|}
\hline \multirow[b]{2}{*}{ Country } & \multicolumn{2}{|c|}{ Obesity $\%$} & \multicolumn{2}{|c|}{ Gonorrhoea, year 2003} & \multicolumn{2}{|c|}{ Syphilis, year 2003} & \multicolumn{2}{|c|}{ Birth rate per 1,000} & \multicolumn{2}{|c|}{$\begin{array}{l}\text { Elective abortion } \\
\text { per } 1,000\end{array}$} \\
\hline & $\begin{array}{l}10-14 \\
\text { years }\end{array}$ & $\begin{array}{l}15-19 \\
\text { years }\end{array}$ & $\begin{array}{l}10-14 \\
\text { years }\end{array}$ & $\begin{array}{l}15-19 \\
\text { years }\end{array}$ & $\begin{array}{l}10-14 \\
\text { years }\end{array}$ & $\begin{array}{l}15-19 \\
\text { years }\end{array}$ & $\begin{array}{l}10-14 \\
\text { years }\end{array}$ & $\begin{array}{l}15-19 \\
\text { years }\end{array}$ & $\begin{array}{l}10-14 \\
\text { years }\end{array}$ & $\begin{array}{l}15-19 \\
\text { years }\end{array}$ \\
\hline Albania & 1.4 & 0.6 & 0 & 2 & 0 & 0 & & & & \\
\hline Bulgaria & 14 & 14 & & & & & 0.748 & 19.29 & & \\
\hline $\mathrm{CZ}$ & 4.95 & 3.7 & 2 & 144 & 1 & 39 & 0.04 & 1.36 & 0.09 & 7.5 \\
\hline Denmark & 2.6 & 3.5 & & & & & & 2.77 & & 7.79 \\
\hline Estonia & 6.5 & 6.09 & 0 & 22 & 0 & 65 & 1 & 48 & 3 & 70 \\
\hline Finland & 12 & 12 & 0 & 10 & 1 & 2 & 0.002 & 10.3 & 0.4 & 14.9 \\
\hline France & 16.50 & 15 & & & & & & & & \\
\hline Georgia & 6 & 5.3 & & & & & & 12 & & 30 \\
\hline Germany & & & & & 1 & 47 & & & 0.4 & 4.9 \\
\hline Greece & 30 & 30 & 15 & 35 & 0 & 2 & & 52 & & \\
\hline Hungary & 7.5 & 12.5 & 11 & 83 & 0 & 10 & 0.15 & 20.7 & 0.33 & 19.2 \\
\hline Israel & & 5.7 & & & & & & 6 & & 7.5 \\
\hline Italy & 6 & 4 & 4 & 60 & 5 & 100 & & 5 & & 7.2 \\
\hline $\begin{array}{l}\text { Latvia } \\
\text { Luxembourg }\end{array}$ & & & 1 & 64 & 4 & 54 & 0.04 & 21.1 & 0.16 & 16.5 \\
\hline Macedonia & 10.07 & 9.8 & 0 & 0 & 0 & 0 & 0.26 & 25.42 & 2.8 & 8.9 \\
\hline Netherlands & & & & $71 *$ & & $9^{*}$ & & $16^{*}$ & & 4.2 \\
\hline Norway & & & 0 & 17 & 0 & 1 & 0.05 & 22.5 & & 16.4 \\
\hline Portugal & & & & & & & & & & \\
\hline Romania & & & 17 & 494 & 59 & 1293 & 0.93 & 35.1 & & \\
\hline Russia & 3 & & & & & & 0.18 & 15.9 & 0.24 & 26.1 \\
\hline Serbia & & & & & & & 0.2 & 25.4 & & \\
\hline Slovenia & 2.4 & 1.4 & 0 & 0 & 0 & 5 & 0.1 & 5.7 & 0.2 & 8.6 \\
\hline Spain & 2.97 & 1.76 & & & & & & 11.4 & & 11.2 \\
\hline Sweden & 3 & 3 & 1 & 46 & 0 & 7 & 0 & 5 & 1 & 23 \\
\hline Switzerland & & 5 & 0 & 20 & 0 & 0 & & 4 & & 5.7 \\
\hline Turkey & 4 & & & & & & 0.75 & 63.16 & & 45 \\
\hline UK & 17 & 19 & 80 & 4970 & 0 & 20 & 3.6 & 38 & 4.5 & 24 \\
\hline Ukraine & & & 152 & 439 & 132 & 690 & 0.03 & 9.47 & 0.1 & 6.6 \\
\hline
\end{tabular}

*10-19 years of age morbidity

special services for this age group if the primary care physicians were able to develop trusting relationships with their teenage patients. In the USA, adolescent medicine is recognised as a certified subspecialty for paediatricians, family physicians and internal medicine physicians, and adolescent medicine divisions are located within or related to the paediatric departments [2]. The WHO offered adolescent-friendly health services staffed by professionals
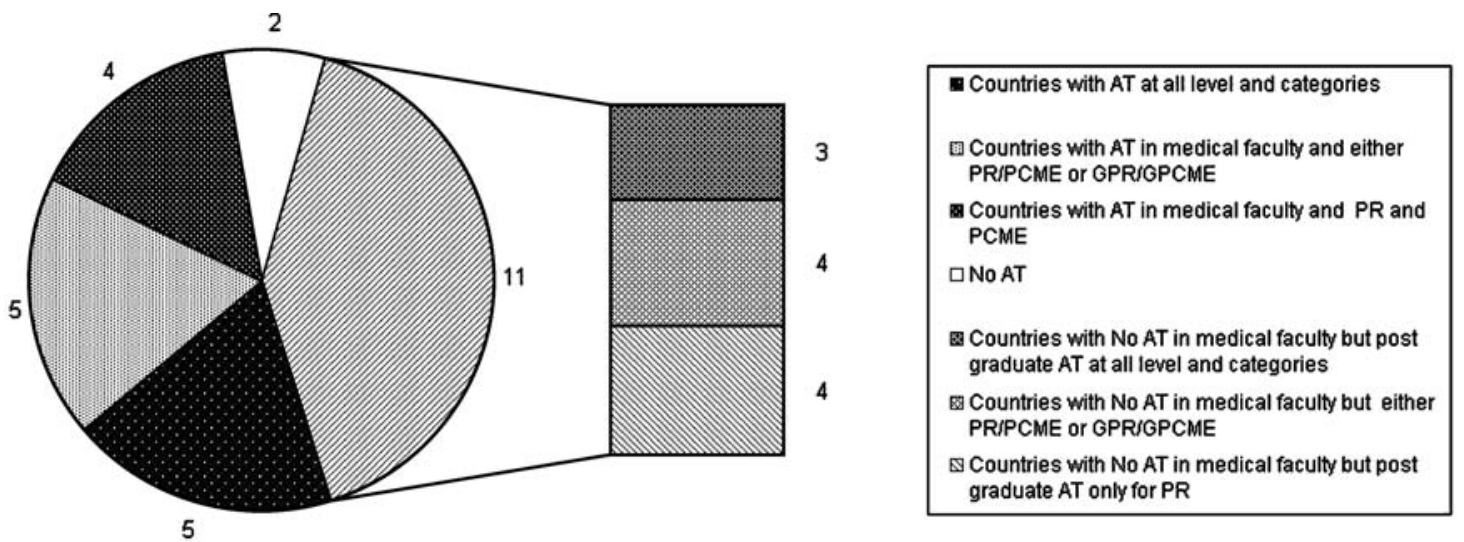

Fig. $2 \mathrm{AT}=$ adolescent training; $\mathrm{PR}=$ paediatric residency; $\mathrm{PCME}=$ paediatric continuous medical education; GPR=general practitioner/family physician residency; GPCME=general practitioner/family physician continuous medical education 
who were trained to look after adolescents [36]. According to the WHO, making services adolescent-friendly was not primarily about setting up separate dedicated services. In this respect, the greatest benefit would come from improving generic health services in local communities and by improving the competencies of health care providers to deal effectively with adolescents. The WHO also stated that health services could help to meet adolescents' needs, but only if they were a part of a comprehensive programme [36]. Our proposal is the integration of a comprehensive adolescent health care programme into the primary health care system in each country. Thus, whoever gives this primary care (whether a paediatrician or a family doctor/ general practitioner) needs to be trained to look after adolescents.

In this study, from the point of view of inpatient care, the upper age limit of adolescents seems to be somewhat higher than that for outpatient care. However, as the upper age limit for hospitalisation in paediatric wards is not uniform, i.e. 18 years, in our sample, still, it appears that adolescents' rights acknowledged under the UN Convention of the Rights of the Child is not fulfilled. Thus, the upper age limit for adolescent inpatient care in paediatric wards, as well as in outpatient care, should be set at 18 years.

Most adolescents require access to universal programmes, such as immunisation, injury prevention, health education, family planning and primary medical care. Accessibility and confidentiality issues are major concerns for teenagers wishing to use services to discuss sensitive issues, such as sexual health $[1,8,13,27,37]$. A study from the UK showed that teenagers found it difficult to consult their GP about their mental health concerns [31]. The results of our study showed that confidentiality is not a uniformly applied practice related to adolescent health care in European countries, as confidential care in sensitive issues such as contraception and HIV was offered in only 20 and 16 of the countries, respectively. Universal programmes should be uniformly given to all adolescents and confidential practice, especially on sensitive issues, should be a part of adolescent health care. This necessitates the reconstruction of adolescent health care delivery in Europe.

\section{Mortality and morbidity}

Our data on mortality and morbidity suggested that there is a lack of standardisation with respect to the collection of data in adolescents in different countries. It is important to obtain standardised data with respect to adolescent mortality and morbidity to follow up the status of adolescent health in Europe.

The presence of a strong correlation between the 1014 years of age and the 15-19 years of age mortality rates and the presence of a correlation between the infant mortality rate and the 10-14 years of age mortality rate, albeit low, suggest that, in 10-14 year olds, adolescent-specific causes and other causes of early childhood mortality are both influential on the 10-14 years of age mortality rate.

In the eastern part of Europe, the 10-14 years of age mortality rate was significantly higher than that in the western part. Those countries which were located in the eastern part of Europe were also those which had a significantly lower GNI than those in the western part of Europe. Thus, higher mortality rates in the eastern countries might be related to lower GNIs in these countries.

The fact that the only relationship found was between the mortality rates and geographical region suggests that it might be necessary to look for new measures possibly for those related to sociopsychocultural and educational differences between countries to evaluate the health status of the adolescent population in Europe.

\section{Organisation of training}

Our data on the demography of training in European countries in adolescent medicine showed that pre-graduate education in adolescent medicine was offered in the context of paediatric curriculum in 14 of the countries. Both the nature and the timing of adolescence give rise to the consideration that paediatrics should be the main discipline to offer education on main adolescent medicine topics.

In our study, there was a difference between general practitioners/family doctors and paediatricians with respect to their training on adolescent medicine in Europe. The sensitisation and training of all professionals involved in the curative and preventive care of adolescents is a crucial factor for the improvement of adolescent health care delivery. Despite the presence of considerable evidence showing that the training needs of health care providers on adolescent medicine were not fulfilled both from the health professional and the user perspectives in different countries $[5,12,14,15,17-22,24-26,32]$, outside the USA, there has been a rather limited systematic approach to training on adolescent medicine until recently [3, 12, 15, 23, 28, 32]. In Europe, the European Training in Effective Adolescent Care and Health programme (EuTEACH; home page at: http://www.euteach.com/) focussed on designing a curriculum that could be used in the training of physicians at both primary and specialty levels to improve adolescent health and well-being in the enlarged European community with a collaborative approach [28].

There is a need for a systematic educational programme aimed at teaching the core knowledge and skill required by health professionals in order to provide developmentally appropriate and user-friendly services for adolescents in Europe. Training in adolescent health could be imple- 
mented for both undergraduates and physicians who would be involved in the care of young people in Europe. A multidisciplinary modular training programme on general and specific aspects of adolescent health could be developed in the light of previous programmes, particularly from that of EuTEACH, which could be implemented in all European countries.

The Czech Republic was the only country which reported that adolescent medicine was a subspecialty of paediatrics with a comprehensive curriculum in adolescent medicine [16]. In the UK, adolescence had been firmly on the health agenda since 1999, but delivering adolescent medicine training to all health professionals, rather than creating a separate specialty, has been the model favoured in the UK [30]. However, the need of a number of specialist adolescent physicians to coordinate adolescent health promotion at all levels and to provide leadership has also been emphasised [30].

Our proposal is that adolescent medicine could be a certified multidisciplinary subspecialty of paediatrics and the European Paediatric Association-UNEPSA could play a key role in supporting the setting up of a certified adolescent medicine subspecialty in paediatrics to ensure the standardisation of training of health professionals and health services given to adolescents across Europe.

\section{Limitations}

There are a few limitations to our study:

- The study covered nearly $65 \%$ of the countries in Europe. This might be seen as a limitation when generalising our results to the whole continent. However, countries that have been surveyed represent $85 \%$ of the total population of EU and $91 \%$ of the population of non-EU countries.

- Some responses were based on estimations and no reliability checks were conducted.

- The areas covered by the questionnaire were restricted to health care and training; questions on other domains, such as research and legal issues related to adolescents, were not included.

- The information was gathered from the national paediatric societies through the patronage of their chief, who might not necessarily be working in the field of adolescent medicine. As this could have resulted in a lack of data, they were asked to collaborate with a distinguished adolescent health specialist from their country in order to respond to the questionnaire in a most accurately as possible manner.

- The number of responding countries to different questions varied; this reduced the power of the statistics and made it difficult to generalise the results across Europe.

\section{Conclusions}

Our results indicated that the programmes and health services for adolescents proposed by the WHO and training in adolescent medicine were not uniformly present in all countries across Europe. To improve this situation, the European Paediatric Association-UNEPSA's suggestions to improve adolescent health care and training are indicated below:

1. Organisation and implementation of a comprehensive adolescent health care programme that respects confidentiality

2. Integration of such a programme into the primary health care system of countries

3. Setting of the upper age limit of paediatric care at 18 years

4. Recognition and approval of adolescent medicine as a subspecialty of paediatrics

Acknowledgements We are indebted to: Helena Fonseca from Portugal, Daniel Hardoff from Israel, Kristina Berg Kelly from Sweden, Pierre André Michaud from Switzerland and JH Tripp from the UK for their e-mail communications and some necessary changes were made according to their contributions.

Participants of the workshop were (in alphabetical order by last name): M. Angastiniotis (Cyprus), N. Arisoy (President, Turkish Paediatric Association), S. Bertelloni (Italy), V. De Sanctis (Italy), B. Fiscina (USA), H. Fonseca (Portugal), D. Hardoff (Israel), C. Kattamis (Greece), J.C. Suris (Switzerland), J. Vejvalka (UNEPSA).

We are indebted to the representatives of the 27 countries for providing us with the data reported in this paper: Kuli-Lito (Albania), Ghenev (Bulgaria), Borch (Denmark), Luts and Ormisson (Estonia), Halila and Honkanen (Finland), Lemerle and Sommelet (France), Constantopoulos (Greece), Manjavidze and Kvezereli (Georgia), Ehrich (Germany), Klujber, Aszmann and Mészner (Hungary), Hardoff and Mimouni (Israel), Bertelloni and Saggese (Italy), Bikis, Karaskevica and Birzule (Latvia), Conter (Luxembourg), Ljupco (Macedonia), Jansen and Schulpen (Netherlands), Hodnekvam and Brunvand (Norway), De Sa and Fonseca (Portugal), Zamfirescu and Dragomir (Romania), Baranov (Russia), Roncevic and Banicevic (Serbia and Montenegro), Brcar and Vidmar (Slovenia), Casas and Castellano (Spain), Melin and Gare (Sweden), Stronski and Klauser (Switzerland), Lukyanova (Ukraine), and Viner and Craft (United Kingdom).

Open Access This article is distributed under the terms of the Creative Commons Attribution Noncommercial License which permits any noncommercial use, distribution, and reproduction in any medium, provided the original author(s) and source are credited.

\section{References}

1. Allaby MA (1995) Contraceptive services for teenagers: do we need family planning clinics? BMJ 310:1641-1643

2. Althouse LA, Stockman JA 3rd (2007) Pediatric workforce: a look at adolescent medicine data from the American Board of Pediatrics. J Pediatr 150:100-102 
3. Bennett DL, Tonkin RS (2003) International developments in adolescent health care: a story of advocacy and achievement. J Adolesc Health 33:240-251

4. Betke K, Ehrich JH, Janda J, Katz M, Rubino A (2007) Thirty years of the Union of National European Paediatric Societies and Associations (UNEPSA). Eur J Pediatr 166:349-357

5. Burack R (2000) Young teenagers' attitudes towards general practitioners and their provision of sexual health care. Br J Gen Pract 50:550-554

6. Burgio GR, Ottolenghi A (1994) Adolescence and paediatrics in Europe. Eur J Pediatr 153:706-711

7. Churchill R, Allen J, Denman S, Williams D, Fielding K, von Fragstein M (2000) Do the attitudes and beliefs of young teenagers towards general practice influence actual consultation behaviour? Br J Gen Pract 50:953-957

8. Donovan C, Mellanby AR, Jacobson LD, Taylor B, Tripp JH (1997) Teenagers' views on the general practice consultation and provision of contraception. The Adolescent Working Group. Br J Gen Pract 47:715-718

9. DuRant RH, Smith KS (2002) Vital statistics and injuries. In: Neinstein LS (ed) Adolescent health care: a practical guide, 4 edn. Lippincot Williams \& Wilkins, Philadelphia, pp 126-169

10. Ehrich JHH, El Gendi AA, Drukker A, Janda J, Stefanidis C, Verrier-Jones K, Collier J, Katz M (2005) Demography of paediatric renal care in Europe: organization and delivery. Nephrol Dial Transplant 20:297-305

11. Elster AB, Kuznets NJ (1994) AMA guidelines for adolescent preventive services (GAPS): recommendations and rationale. Williams \& Wilkins, Baltimore

12. Emans SJ, Bravender T, Knight J, Frazer C, Luoni M, Berkowitz C, Armstrong E, Goodman E (1998) Adolescent medicine training in pediatric residency programs: are we doing a good job? Pediatrics 102:588-595

13. Garside R, Ayres R, Owen M, Pearson VAH, Roizen J (2002) Anonymity and confidentiality: rural teenagers' concerns when accessing sexual health services. J Fam Plann Reprod Health Care 281:23-26

14. Hardoff D, Tamir A, Palti H (1999) Attitudes and practices of Israeli physicians toward adolescent health care: a national survey. J Adolesc Health 25:35-39

15. Igra V, Millstein SG (1993) Current status and approaches to improving preventive services for adolescents. JAMA 269:1408-1412

16. Institut postgraduálního vzdělávání ve zdravotnictví (IPVZ) (2005-2007) Home page at: http://www.ipvz.cz/adolescentmedicine

17. Jacobson L, Kinnersley $P$ (2000) Teenagers in primary carecontinuing the new direction. Br J Gen Pract 50:947-948

18. Jacobson LD, Mellanby AR, Donovan C, Taylor B, Tripp JH (2000) Teenagers' views on general practice consultations and other medical advice. The Adolescent Working Group, RCGP. Fam Pract 17:156-158

19. Jacobson L, Richardson G, Parry-Langdon N, Donovan C (2001) How do teenagers and primary healthcare providers view each other? An overview of key themes. Br J Gen Pract 51:811-816

20. Jacobson L, Churchill R, Donovan C, Garralda E, Fay J; Adolescent Working Party, RCGP (2002) Tackling teenage turmoil: primary care recognition and management of mental ill health during adolescence. Fam Pract 19:401-409

21. Jones R, Finlay F, Simpson N, Kreitman T (1997) How can adolescents' health needs and concerns best be met? Br J Gen Pract 47:631-634

22. Kang M, Bernard D, Booth M, Quine S, Alperstein G, Usherwood T, Bernett D (2003) Access to primary health care for Australian young people: service provider perspectives. $\mathrm{Br} \mathrm{J}$ Gen Pract 53:947-952

23. Katz M, Rubino A, Collier J, Rosen J, Ehrich JH (2002) Demography of pediatric primary care in Europe: delivery of care and training. Pediatrics 109:788-796

24. Kraus B, Stronski S, Michaud PA (2003) Training needs in adolescent medicine of practising doctors: a Swiss national survey of six disciplines. Med Educ 37:709-714

25. McDonagh JE, Southwood TR, Shaw KL; British Paediatric Rheumatology Group (2004) Unmet education and training needs of rheumatology health professionals in adolescent health and transitional care. Rheumatology (Oxford) 43:737743

26. McDonagh JE, Minnaar G, Kelly K, O'Connor D, Shaw KL (2006) Unmet education and training needs in adolescent health of health professionals in a UK children's hospital. Acta Paediatr 95:715-719

27. McKee MD, O'Sullivan LF, Weber CM (2006) Perspectives on confidential care for adolescent girls. Ann Fam Med 4:519-526

28. Michaud PA, Stronski S, Fonseca H, Macfarlane A; EuTEACH Working Group (2004) The development and pilot-testing of a training curriculum in adolescent medicine and health. J Adolesc Health 35:51-57

29. Parliamentary Assembly, Council of Europe (PACE). Home page at: http://assembly.coe.int/ASP/AssemblyList/AL_Delegations List_E.asp)

30. Payne D, Martin C, Viner R, Skinner R (2005) Adolescent medicine in paediatric practice. Arch Dis Child 90:1133-1137

31. Potts Y, Gillies ML, Wood SF (2001) Lack of mental well-being in 15-year-olds: an undisclosed iceberg? Fam Pract 18:95-100

32. Sanci LA, Coffey CM, Veit FC, Carr-Gregg M, Patton GC, Day $\mathrm{N}$, Bowes G (2000) Evaluation of the effectiveness of an educational intervention for general practitioners in adolescent health care: randomised controlled trial. BMJ 320:224-230

33. The United Nations Convention on the Rights of the Child (UNCRC) 1989

34. The United Nations Convention on the Rights of the Child (UNCRC) 1989. Articles 5, 12, 17, 19, 24 and 29

35. The World Bank (2008) Gross national income (GNI). Available online at: http://www.worldbank.org/data/countryclass.htm

36. World Health Organization (WHO) (2002) Adolescent friendly health services. An agenda for change. WHO, Geneva, Switzerland, WHO/FCH/CAH/02.14. Available online at: http://www.who.int/reproductive-health/publications/cah_docs/ cah_02_14.pdf

37. WHO/Europe (2005) The European strategy for child and adolescent health and development. Home page at: http://www. euro.who.int/childhealthdev 